\title{
Natureza das dificuldades de leitura em crianças brasileiras com dislexia do desenvolvimento
}

\section{Nature of reading difficulties in Brazilian children with development dyslexia}

\author{
Alessandra Gotuzo Seabra CAPOVILLA \\ Bruna Tonietti TREVISAN \\ Fernando César CAPOVILLA \\ Maria do Carmo Alves de REZENDE
}

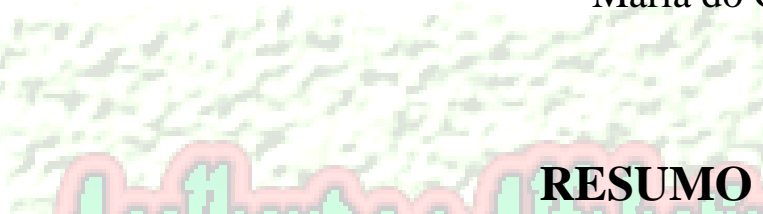

Segundo uma abordagem de processamento de informação, diferentes estratégias de leitura prevalecem em diferentes estágios, dependendo das características da escrita. No primeiro estágio, logográfico, prevalece a estratégia logográfica, em que o reconhecimento é limitado a umas poucas palavras familiares e dificultado por paralexias. No segundo, alfabético, prevalece a estratégia fonológica de decodificação grafemafonema, que permite a leitura de palavras novas, desde que sejam regulares grafofonemicamente. No terceiro, ortográfico, prevalece a estratégia lexical de reconhecimento visual direto, que permite ler palavras grafofonemicamente irregulares, desde que sejam familiares. O Teste de Competência de Leitura de Palavras e Pseudopalavras (TCLPP) analisa, sistematicamente, a habilidade de usar cada estratégia. Compõe-se de sete tipos de pares figura-escrita, i.e., uma figura associada a uma palavra ou pseudopalavra. A tarefa é circular os pares corretos e cruzar os incorretos. Os dois primeiros consistem de palavras grafofonemicamente regulares ou irregulares associadas a suas correspondentes figuras. Os cinco últimos consistem de palavras associadas a figuras diferentes, ou a pseudopalavras de quatro tipos: pseudopalavras com pronúncia idêntica à de palavras; pseudopalavras com aspecto similar ao de palavras; pseudopalavras com pronúncia similar em relação à de palavras; e pseudopalavras sem semelhança visual ou fonológica com palavras. Usando TCLPP, o estudo analisou estratégias de leitura de 13 disléxicos, comparando-as às de 2196 normoléxicos de $1^{\text {a. }}-7^{\text {a. }}$ série. Resultados mostraram que as dificuldades são 
basicamente fonológicas. Disléxicos foram tão bem quanto normoléxicos na leitura de palavras, mas significativamente pior na de pseudopalavras, especialmente naquelas com aspecto similar ao de palavras e naquelas com pronúncia similar à de palavras. O estudo corroborou a noção de que o processamento fonológico é o principal quesito de leitura e escrita alfabéticas, e que distúrbios naquele processamento são responsáveis pelas dificuldades específicas de leitura que caracterizam a dislexia do desenvolvimento.

Palavras-chave: Dislexia, fonologia, Português, ortografia.

\begin{abstract}
According to an information processing approach, different reading strategies prevail at different stages and depending on print characteristics. The first stage, logographic, is marked by the prevalence of the logographic strategy in which recognition is limited to a few familiar words and plagued with paralexias. The second stage, alphabetical, is marked by the prevalence of a phonological strategy, based on grapheme-phoneme decoding, which permits reading new words, provided their spelling is regular. The third stage, orthographic, is marked by the prevalence of a lexical strategy, based on visual recognition, which permits reading irregularly-spelled words, provided they are familiar. Reading Competence Test (RCT) analyzes systematically the ability of using each strategy. RTC is made of seven types of print-picture pairs, i.e., a print (either a word or a nonword) associated with a picture. The task is to circle correct print-picture pairs and to cross out incorrect ones. The former consist of either regularly-spelled words or irregularly-spelled words associated with their corresponding pictures. The latter consist of either words associated with unrelated pictures, or nonwords of four types: nonwords that sound like words, nonwords that look similar to words, nonwords that sound similar to words, nonwords that neither sound nor look similar to words. Using RCT, this study analyzed reading strategies used by 13 dyslexic children and compared them to those used by $21961^{\text {st }}-7^{\text {th }}$ grade normolexic students. Results revealed that the difficulty presented by dyslexic children is eminently phonological: In word reading, dyslexic children performed equivalent to normolexic children, whereas in nonword reading, they performed significantly worse, especially for nonwords that look or sound similar to words. The study corroborated the notion that phonological processing is a major component of alphabetical reading and spelling, and that phonological processing disorders are mainly responsible for the specific reading difficulties that characterize developmental dyslexia.
\end{abstract}

Index Terms: Dyslexia, phonology, Portuguese, orthography. 


\section{Introdução}

Os distúrbios de leitura e escrita atingem, de forma severa, cerca de $10 \%$ das crianças em idade escolar. Se forem considerados também os distúrbios leves, este percentual chega a 25\% (PIÉRART, 1997). Logo, uma das tarefas mais freqüentes de psicólogos, psicopedagogos e profissionais de áreas afins é a avaliação de distúrbios de leitura. É essencial, portanto, que o profissional conheça os vários tipos de distúrbios de leitura, possa conduzir o diagnóstico diferencial entre eles e, com base neste diagnóstico, realize a intervenção apropriada.

Conforme descrito por Grégoire (1997), o distúrbio específico de leitura é geralmente chamado de dislexia nos países de língua francesa e de distúrbio de leitura (reading disability) nos países de língua inglesa. Apesar das divergências quanto ao nome da síndrome, há uma razoável concordância sobre sua definição. Segundo a World Federation of Neurologists (1968), dislexia do desenvolvimento é o distúrbio em que a criança, apesar de ter acesso à escolarização regular, falha em adquirir as habilidades de leitura, escrita e soletração que seriam esperadas, de acordo com seu desempenho intelectual. Segundo a definição do National Institute of Health americano, a dislexia é "um dos vários tipos de distúrbios de aprendizagem. É um distúrbio específico de linguagem de origem constitucional e caracterizado por dificuldades em decodificar palavras isoladas, geralmente refletindo habilidades de processamento fonológico deficientes. Essas dificuldades em decodificar palavras isoladas são freqüentemente inesperadas em relação à idade e outras habilidades cognitivas e acadêmicas, elas não são resultantes de um distúrbio geral do 
desenvolvimento ou de problemas sensoriais." (THE ORTON DYSLEXIA SOCIETY, 1995, p. 2).

Para diagnosticar a dislexia do desenvolvimento, deve ser excluída a presença de alguns outros distúrbios. Segundo Tallal et al. (1997), a dislexia caracteriza-se por um distúrbio na linguagem expressiva e/ou receptiva que não pode ser atribuído a atraso geral do desenvolvimento, distúrbios auditivos, lesões neurológicas importantes (como paralisia cerebral e epilepsia) ou distúrbios emocionais.

Além da dislexia do desenvolvimento, anteriormente descrita, há a dislexia adquirida, também denominada de alexia. Nas dislexias adquiridas, a perda da habilidade de leitura é devida a uma lesão cerebral específica e ocorre após o domínio da leitura pelo indivíduo. Nas dislexias do desenvolvimento, ao contrário, não há uma lesão cerebral evidente, e a dificuldade já surge durante a aquisição da leitura pela criança. A divisão clássica dos tipos de dislexia foi feita com base nos quadros de dislexia adquirida, e baseia-se em qual etapa, ao longo do processamento de informação, está afetada (MORAIS, 1995). De acordo com Frith (1985), este processamento da informação escrita pode ocorrer por meio de três estratégias: a logográfica, a alfabética e a ortográfica.

$\mathrm{Na}$ primeira delas, a logográfica, a leitura e a escrita ainda são incipientes, pois se caracterizam pelo uso de pistas contextuais e nãolingüísticas. Sem estas pistas, o reconhecimento não é possível. As cores, o fundo e a forma das palavras são algumas das pistas utilizadas para a leitura logográfica. Nesta estratégia, o leitor relaciona a palavra com seu contexto específico e a palavra é tratada como um desenho. Um exemplo dessa estratégia é a leitura dos rótulos mais comuns no dia-a-dia do leitor. 
A segunda estratégia, a alfabética, com o desenvolvimento da rota fonológica, implica o conhecimento das correspondências entre letras e fonemas, durante a codificação e a decodificação. Aqui, a palavra não é mais tratada como um desenho e sim como um encadeamento de unidades menores (letras ou sons) que, unidas, resultam em uma unidade maior e com significado (a palavra). Assim, nesta estratégia, o leitor é capaz de converter o som em escrita (e vice-versa), conseguindo ler e escrever palavras novas e pseudopalavras.

Num primeiro momento, a leitura alfabética pode ser sem compreensão porque, apesar da conversão letra-som, o significado não é alcançado, visto que os recursos centrais de atenção e memória estão totalmente voltados à tarefa de decodificação grafo-fonêmica. Num segundo momento, com a automatização da decodificação, o leitor consegue ter acesso ao significado.

Finalmente, na estratégia ortográfica, os níveis lexical e morfêmico são reconhecidos diretamente, sem a necessidade de conversão fonológica, de modo que a leitura caracteriza-se pelo processamento visual direto das palavras. Nesta etapa, a partir da representação ortográfica, a criança tem acesso direto ao sistema semântico. Ou seja, o leitor já possui um léxico mental ortográfico, podendo relacionar a palavra escrita diretamente ao seu significado, fazendo uma leitura competente. Torna-se possível a leitura de palavras irregulares.

Tais estratégias não são mutuamente excludentes e podem coexistir simultaneamente no leitor e no escritor competentes. A estratégia a ser utilizada, em qualquer dado momento, depende do tipo de item a ser lido ou escrito, sendo influenciada pelas características psicolingüísticas dos itens, tais como lexicalidade, freqüência, regularidade grafo-fonêmica e comprimento (CAPOVILLA; CAPOVILLA, 2000b, MORAIS, 1995). 
Como anteriormente descrito, a divisão dos tipos de dislexia foi feita com base nos quadros de dislexia adquirida, e baseia-se em qual etapa está afetada, ao longo do processamento de informação, por meio das três estratégias de leitura (MORAIS, 1995). Os principais quadros são:

Dislexia visual. Há distúrbios na análise visual das palavras. Os erros de leitura mostram uma semelhança visual entre a escrita da palavra pronunciada e a da palavra alvo. Por exemplo, diante de "bandagem" ler "bobagem".

Dislexia de negligência. Os distúrbios também estão no sistema de análise visual, e o leitor consistentemente ignora partes das palavras, geralmente deixando de ler a parte inicial.

Leitura letra-a-letra. Há distúrbios no reconhecimento global de palavras, ou seja, no processamento paralelo das letras. A leitura é feita corretamente somente após a soletração (em voz alta ou não) de cada letra. Há dificuldade com letras cursivas, pois a separação das letras é menos evidente, sendo mais fácil ler palavras escritas em letra de fôrma.

Dislexia atencional. Há dificuldades na codificação das posições das letras nas palavras, mas a identificação paralela das letras está preservada. Assim, pode haver migrações de letras dentro de uma mesma palavra ou, principalmente, de uma palavra a outra durante a leitura de frases.

Dislexia fonológica. Há dificuldades na leitura pela estratégia alfabética, que faz uso do processamento fonológico. Porém, a leitura visual-direta pela estratégia ortográfica está preservada. Logo, há dificuldades na leitura de pseudopalavras e palavras desconhecidas, mas a leitura de palavras familiares é adequada. Representa cerca de $67 \%$ dos quadros disléxicos (BODER, 1973). 
Dislexia morfêmica ou semântica. Há dificuldades na leitura pela estratégia ortográfica, sendo a leitura feita principalmente pela estratégia alfabética. Logo, há dificuldades na leitura de palavras irregulares e longas, com regularizações. Representa cerca de $10 \%$ dos quadros disléxicos.

Esta divisão, feita inicialmente a partir dos quadros de dislexias adquiridas, tem sido aplicada também às dislexias do desenvolvimento, especialmente a distinção entre a dislexia fonológica e a dislexia morfêmica, ou seja, o distúrbio alfabético e o distúrbio ortográfico (STANOVICH; SIEGEL; GOTTARDO, 1997). Porém, os achados mais recentes sobre os tipos de dislexia têm sido mais negativos que positivos, ou seja, há cada vez menos evidências de que as dislexias do desenvolvimento tenham, de fato, diferentes tipos com padrões de leitura distintos entre si. Ao contrário, as pesquisas têm sugerido que as dislexias do desenvolvimento caracterizamse, basicamente, pelos distúrbios na leitura alfabética, e não pelos distúrbios na leitura ortográfica. A dislexia morfêmica seria mais o resultado de um atraso geral da leitura do que de um padrão desviante. Será abordado, a seguir, um dos estudos que confirmam tal suposição.

Stanovich, Siegel e Gottardo (1997) avaliaram 68 crianças disléxicas em tarefas de leitura de palavras irregulares (i.e., com relações entre letra e som imprevisíveis, como táxi) e de pseudopalavras. Enquanto a leitura de palavras irregulares só pode ser feita corretamente pela rota lexical, a leitura de pseudopalavras só pode ser feita corretamente pela rota fonológica. Com base nos resultados, as crianças foram divididas em três grupos: disléxicas fonológicas (que apresentavam pobre leitura de pseudopalavras mas boa leitura de palavras irregulares), disléxicas morfêmicas (boa leitura de pseudopalavras mas pobre leitura de palavras irregulares) e disléxicas mistas (leitura similar em ambas as tarefas). 
Tais crianças foram, então, comparadas a 44 crianças-controle nãodisléxicas. Ambos os grupos tinham o mesmo nível de leitura, ou seja, foi controlado o efeito da exposição à leitura e as possíveis conseqüências que tal exposição poderia ter sobre o desenvolvimento cognitivo das crianças. Assim, enquanto as crianças disléxicas freqüentavam a $3^{\mathrm{a}}$. série, as crianças não-disléxicas freqüentavam da $1^{\mathrm{a}}$ à $2^{\mathrm{a}}$ série.

Quando os resultados das crianças disléxicas foram comparados aos resultados das crianças não-disléxicas com mesmo nível de leitura, mas idade cronológica inferior, foi observado que:

a. os disléxicos morfêmicos apresentaram um padrão de leitura bastante similar ao padrão das crianças-controle mais novas em idade cronológica, mas com mesmo nível de leitura. Ou seja, os disléxicos morfêmicos tinham mais um atraso na leitura do que um desvio;

b. os disléxicos fonológicos apresentaram, de fato, um padrão desviante. Seus desempenhos não foram similares aos de crianças mais jovens. Ao contrário, enquanto sua leitura lexical foi significativamente superior à do grupo controle mais jovem, sua leitura fonológica foi significativamente inferior. Ou seja, apesar do escore geral ter sido o mesmo entre o grupo controle e o grupo de disléxicos fonológicos, a distribuição dos escores foi diferente.

Além do desempenho em leitura, os disléxicos morfêmicos apresentaram desempenhos semelhantes ao grupo controle mais jovem em habilidades de consciência fonológica, processamento sintático e memória de trabalho. Por outro lado, os disléxicos fonológicos tiveram desempenhos rebaixados em relação às crianças de mesmo nível de leitura nestas três habilidades. 
Este estudo sugere, portanto, que a dislexia fonológica é, realmente, um padrão desviante de leitura, enquanto a dislexia morfêmica parece ser mais um atraso na leitura, apresentando um padrão consistente com um nível de leitura menos desenvolvido. Os disléxicos fonológicos parecem ter, na verdade, um processamento fonológico alterado, que não pode ser simplesmente devido à falta de exposição à leitura.

Outro achado do estudo é que grande parte dos disléxicos apresenta um perfil misto, isto é, apresentam dificuldades significativas em ambas as rotas fonológica e lexical. Porém, essa proporção de disléxicos mistos é maior com crianças jovens $(27,9 \%)$ do que com crianças mais velhas $(9,8 \%)$, sendo que os disléxicos jovens mistos podem evoluir para disléxicos fonológicos quando mais velhos. Tal evolução provavelmente ocorre porque essas crianças conseguem desenvolver habilidades de leitura lexical, com estratégias de reconhecimento visual, diminuindo, portanto, suas dificuldades com palavras irregulares de alta freqüência.

Sumariando, há uma diversidade de quadros disléxicos que podem ocorrer, e há evidências de que os problemas alfabéticos são os mais freqüentes entre os disléxicos de ortografias alfabéticas. Neste contexto, a presente pesquisa teve como objetivo verificar, em crianças disléxicas brasileiras, quais são as estratégias de leitura mais comprometidas. Conforme o arrazoado teórico anteriormente exposto, visto que a língua portuguesa possui uma ortografia razoavelmente transparente, seria esperado que o principal comprometimento de crianças disléxicas ocorresse na leitura alfabética.

\section{Método}

\subsection{Participantes}


Participaram do presente estudo 13 crianças com diagnóstico de dislexia, sem especificação de tipo, e 2196 crianças sem tal diagnóstico, cursando da $1^{\text {a }}$ à $7^{\text {a }}$ série do ensino fundamental de escolas públicas e particulares do estado de São Paulo.

\subsection{Instrumento}

\subsubsection{Teste de Competência de Leitura Silenciosa}

O Teste de Competência de Leitura Silenciosa - TeCoLeSi (CAPOVILLA et al, 2004) é um instrumento neuropsicológico e psicométrico para a avaliação da competência de leitura silenciosa. Ele possui oito tentativas de treino e 70 de teste, cada qual com um par composto de uma figura e de um item escrito. A tarefa da criança é circular os pares figura-escrita corretos e marcar com um $\mathrm{X}$ os pares figura-escrita incorretos.

Existem sete tipos de pares, distribuídos aleatoriamente ao longo do teste, com dez itens de teste para cada tipo de par. Eles são: 1. palavras corretas regulares, como FADA, sob a figura de uma fada; 2. palavras corretas irregulares, como TÁXI, sob a figura de um táxi; 3. palavras com incorreção semântica, como TREM, sob a figura de um ônibus; 4. pseudopalavras com trocas visuais, como CAEBÇA, sob a figura de cabeça; 5 . pseudopalavras com trocas fonológicas, CANCURU, sob a figura de um canguru; 6. pseudopalavras homófonas, PÁÇARU, sob a figura de um pássaro; e 7. pseudopalavras estranhas, como RASSUNO, sob a figura de uma mão.

Os pares figura-escrita compostos de palavras corretas regulares e irregulares devem ser aceitas, enquanto que as de incorreção semântica ou de pseudopalavras devem ser rejeitadas. O padrão de erros em cada tipo de item pode ser indicativo sobre quais estratégias de leitura a criança usa e 
em quais ela tem dificuldade. Assim, conforme descrito por Capovilla e Capovilla (2004):

- erro na aceitação de palavras corretas irregulares pode indicar dificuldade com o processamento lexical, ou falta dele;

- erro na rejeição de pseudopalavras homófonas pode indicar a mesma dificuldade com o processamento lexical, ou falta dele, num nível ainda mais acentuado, com uso exclusivo da rota fonológica;

- erro na rejeição de pseudopalavras com trocas fonológicas poderia indicar a mesma falta de recurso ao léxico, mas com o agravante de dificuldades com o processamento fonológico;

- erro na rejeição de palavras semanticamente incorretas poderia indicar falta de acesso ao léxico semântico;

- erro na rejeição de pseudopalavras com trocas visuais poderia indicar dificuldade com o processamento fonológico, e recurso à estratégia de leitura logográfica; e

- finalmente, erro na rejeição de pseudopalavras estranhas poderia indicar sérios problemas de leitura.

Devido às relações intrínsecas ao Teste de Competência de Leitura Silenciosa, ou seja, entre os sete tipos de pares figura-escrita, este instrumento permite uma checagem interna das conclusões e uma certa validação cruzada das evidências fornecidas em cada tipo de par figuraescrita. 


\subsection{Procedimento}

$\mathrm{O}$ TeCoLeSi foi aplicado individualmente às 13 crianças com diagnóstico de dislexia. Às 1200 crianças sem o diagnóstico de dislexia, o instrumento foi aplicado coletivamente, em sala de aula.

\section{Resultados e discussão}

Foi conduzida Análise de Covariância, tendo como fator o grupo (disléxicos e não-disléxicos), como covariante a série escolar, e como variáveis dependentes os escores médios em cada subteste e total no TeCoLeSi. A Tabela 1, a seguir, sumaria os resultados encontrados. De forma sucinta, as análises conduzidas evidenciaram que as crianças disléxicas apresentaram um escore total levemente inferior ao das crianças não-disléxicas, com $\mathrm{F}(1,2206)=4,01, \mathrm{p}<0,045$. No entanto, a análise da freqüência de acerto em cada subteste do Teste de Competência de Leitura Silenciosa revelou que o desempenho dos disléxicos foi semelhante aos dos não-disléxicos na leitura de palavras, porém inferior na leitura de pseudopalavras, especialmente nas pseudopalavras com trocas fonológicas ou visuais.

Tabela 1. Escores médios e erros-padrão entre parênteses no TeCoLeSi total e em cada subteste para o grupo de crianças disléxicas e não disléxicas.

\begin{tabular}{ccc}
\hline \hline TeCoLeSi & Não-Disléxicos & Disléxicos \\
\hline Total & $0,863(0,002)$ & $0,803(0,030)$ \\
CR & $0,924(0,003)$ & $0,923(0,037)$ \\
CI & $0,836(0,004)$ & $0,848(0,049)$ \\
VS & $0,958(0,002)$ & $0,963(0,028)$ \\
VV & $0,877(0,004)$ & $0,751(0,047)$ \\
VF & $0,792(0,005)$ & $0,616(0,059)$ \\
PH & $0,696(0,005)$ & $0,539(0,068)$ \\
PE & $0,968(, 002)$ & $0,981(0,026)$ \\
\hline \hline
\end{tabular}


Assim, analisando o desempenho de ambos os grupos no TeCoLeSi e em cada um de seus subtestes, evidencia-se que:

a. Não houve diferença significativa entre ambos os grupos nas palavras corretas regulares (CR), $\operatorname{com} p=0,98$. Tal fato pode ser explicado pela possibilidade das palavras corretas regulares serem lidas por qualquer uma das três estratégias de leitura: logográfica, alfabética ou ortográfica;

b. Não houve diferença significativa entre os grupos nas palavras corretas irregulares (CI), com $p=0,81$. Interessante observar, no entanto, que apesar de diferença não significativa, o grupo disléxico obteve desempenho superior ao grupo não disléxico neste subteste. Vale lembrar que as palavras irregulares podem ser lidas corretamente pelas estratégias logográfica ou ortográfica, mas, se fossem lidas pela alfabética, seriam ocasionados erros de regularização. Deste modo, este resultado pode ser indicativo de que as estratégias logográfica ou lexical encontram-se preservadas nestes sujeitos;

c. Não houve diferença entre os grupos nas palavras com incorreção semântica (VS), com $p=0,84$, o que pode sugerir adequado acesso ao léxico semântico. É interessante observar que as palavras com incorreção semântica também podem ser lidas por qualquer uma das três estratégias, dentre logográfica, alfabética e ortográfica;

d. Diferenças significativas entre os grupos foram encontradas nas pseudopalavras com trocas visuais (VV), $\operatorname{com} F(1,2206)=7,28$, $p=0,007$, tendo o grupo disléxico desempenho inferior ao grupo não-disléxico. Este padrão de desempenho sugere dificuldade 
com o processamento fonológico, uma vez que, se realizasse a decodificação grafofonêmica, o indivíduo perceberia as trocas visuais sem maiores dificuldades. Além das possíveis dificuldades com o processamento fonológico, este padrão indica recurso à estratégia logográfica de leitura, através de um reconhecimento visual global de palavras visualmente semelhantes;

e. Diferenças significativas entre os grupos disléxico e não-disléxico foram observadas nas pseudopalavras com trocas fonológicas (VF), $F(1,2206)=9,01, p=0,003$, com o grupo disléxico apresentando desempenho inferior ao grupo não-disléxico. Tal achado sugere dificuldade ou falta de recurso ao léxico, uma vez que a leitura por processamento visual direto e a comparação do item escrito com sua representação pré-armazenada no léxico ortográfico deveria mostrar-se eficiente na rejeição deste tipo de item; tal padrão pode ser indicativo, também, de dificuldades no processamento fonológico, pois o leitor aceita as trocas fonológicas como corretas;

f. Diferenças significativas foram encontradas entre os grupos para as pseudopalavras homófonas $(\mathrm{PH}), \operatorname{com} F(1,2206)=5,35, p=$ 0,021, com o grupo disléxico apresentando desempenho inferior ao do grupo não-disléxico. No geral, dificuldades na rejeição das pseudopalavras homófonas podem ser tomadas como indicativo de dificuldades no processamento lexical, com uso exclusivo do processamento fonológico. No entanto, uma análise mais cuidadosa evidencia que o escore do grupo disléxico, neste item específico, aproxima-se muito da faixa de acertos ao acaso. Somado a este fato, pode-se tomar o desempenho do mesmo grupo em outros subtestes $(\mathrm{VV}, \mathrm{VF})$ do instrumento então 
utilizado, como indicativo de uma leitura por similaridade visual; $\mathrm{e}$

g. Por fim, não houve diferença significativa entre ambos os grupos avaliados nas pseudopalavras estranhas (PE), com $p=0,62$. Tal fato é corroborado pela possibilidade de uso de qualquer estratégia de leitura (logográfica, alfabética ou ortográfica) na leitura de tais itens.

Desta forma, e considerando o padrão de desempenho do grupo disléxico em cada subteste do Teste de Competência de Leitura Silenciosa, como descrito até então, pode-se observar nestes sujeitos um padrão de leitura visual global, com bom desempenho nas palavras corretas (regulares e irregulares), mas se deixando enganar por trocas sutis que mantenham o mesmo aspecto geral do item escrito, o que poderia ser facilmente identificado através de um adequado processo de decodificação grafofonêmica ou através do acesso ao léxico ortográfico. Ou seja, as crianças disléxicas da presente amostra estão fazendo uso, basicamente, da estratégia de leitura logográfica, sem uso competente das estratégias alfabética ou ortográfica.

\section{Considerações finais}

Sumariando, as crianças disléxicas apresentaram um escore total levemente inferior ao das crianças não-disléxicas. A análise dos escores específicos em cada subteste revelou que o desempenho dos disléxicos foi semelhante aos dos não-disléxicos na leitura de palavras, mas inferior na leitura de pseudopalavras, especialmente daquelas que envolviam trocas fonológicas ou visuais. 
Portanto, os resultados obtidos sugerem que a dificuldade das crianças disléxicas é especialmente evidente quando a leitura não pode ser feita unicamente pela estratégia logográfica, mas é necessário usar a decodificação ou o reconhecimento ortográfico, visto que o item a ser lido, por ser uma pseudopalavra, não faz parte do vocabulário visual cotidiano da criança.

Tal padrão de leitura é compatível com o arrazoado teórico anteriormente descrito sobre o desenvolvimento das estratégias de leitura. $\mathrm{Ou}$ seja, como as crianças apresentam grande dificuldade com o processamento fonológico, permanecem num estilo basicamente logográfico de leitura, sem conseguir dominar a leitura alfabética e, conseqüentemente, avançar para a leitura ortográfica.

Os resultados apresentados no presente capítulo corroboram evidências oriundas de outros estudos (e.g. CAPOVILLA; CAPOVILLA, 2000a, 2000b, 2004), os quais indicam que as dificuldades em leitura e escrita se devem, em grande parte, a problemas iniciais de processamento fonológico. Estudos brasileiros têm mostrado que tais dificuldades podem ser significativamente diminuídas com a incorporação precoce de atividades fônicas logo no início da alfabetização (CAPOVILLA, 2003).

Neste sentido, este estudo estende sua relevância à implementação de procedimentos interventivos, uma vez que tais dados podem ainda auxiliar o desenvolvimento de procedimentos de intervenção que visem à prevenção e ao tratamento das dislexias, tornando-os mais eficazes ao trabalharem com as dificuldades subjacentes a tais problemas. 


\section{Referências bibliográficas}

BODER, E. (1973). Developmental dyslexia: A diagnostic approach based on three atypical reading-spelling patterns. Developmental Medicine and Child Neurology, Londres, v. 15, p. 663-687.

CAPOVILLA, A. G. S. (2003). A eficácia das instruções fônicas. Revista de educação Ceap, Salvador, v. 40, n. 11, p. 56-58.

CAPOVILlA, A. G. S., CAPOVILlA, F. C. (2000a). Efeitos do treino de consciência fonológica em crianças com baixo nível sócio-econômico. Psicologia: reflexão e crítica, Porto Alegre, v. 13, n. 1, p. 7-24.

(2000b). Problemas de leitura e escrita: Como identificar, prevenir e remediar numa abordagem fônica. São Paulo: Memnon, Edipusp, Fapesp.

(2004). Alfabetização: método fônico. 3. ed. São Paulo: Memnon.

CAPOVILLA, F. C. et al (2004). Como avaliar o desenvolvimento da competência de leitura de palavras em surdos do Ensino Fundamental ao Médio, e analisar processos de reconhecimento e decodificação: Teste de Competência de Leitura de Palavras. In: ; RAPHAEL, W. (Orgs.).

Enciclopédia da Língua de Sinais Brasileira: o mundo do surdo em Libras, v. 1. São Paulo: Edusp, Fundação Vitae, Feneis, Capes, CNPq, Fapesp, p. 297-680.

GRÉGOIRE, J. (1997). O diagnóstico dos distúrbios de aquisição de leitura. In: __ _ PIÉRART, B. (Orgs.). Avaliação dos problemas de leitura: os novos modelos diagnósticos e suas implicações diagnósticas. Porto Alegre: Artes Médicas, p. 35-52.

MORAIS, J. (1995). A arte de ler. São Paulo: Unesp.

PIÉRART, B. (1997). As dislexias do desenvolvimento: uma virada conceptual e metodológica nos modelos dos distúrbios de leitura na criança. In: GRÉGOIRE, J.; PIÉRART, B. (Orgs.). Avaliação dos problemas de leitura: Os novos modelos diagnósticos e suas implicações diagnósticas. Porto Alegre: Artes Médicas, p. 11-18.

STANOVICH, K. E.; SIEGEL, L. S.; GOTTARDO, A. (1997). Progress in the search for dyslexics sub-types. In: HULME, C.; SNOWLING, M. (Orgs.). Dyslexia: Biology, Cognition and Intervention. London: Whurr Publishers Ltd, p. 108-130. 
TALLAL, P. et al. (1997). Academic outcomes of language impaired children. In: HULME, C.; SNOWLING, M. (Orgs.). Dyslexia: biology, cognition and intervention. London: Whurr Publishers Ltd, p. 167-181.

THE ORTON DYSLEXIA SOCIETY (1995). Definition adopted by general membership. Baltimore: The Orton Dyslexia Society.

WORLD FEDERATION OF NEUROLOGISTS (1968). Report of research group on dyslexia and world illiteracy. Dallas: WFN.

\section{Autores}

\section{Alessandra Gotuzo Seabra Capovilla}

Doutora e Pós-Doutorada em Psicologia Experimental pela Universidade de São Paulo

Docente, pesquisadora e orientadora do Programa de Pós-Graduação Stricto Sensu em Psicologia da Universidade São Francisco

Telefone: (11) 4534-8040, fax: (11) 4524-1933

Rua Alexandre Rodrigues Barbosa, 45 - Itatiba - SP - 13251-040

acapovil@usp.br

\section{Bruna Tonietti Trevisan}

Bolsista do Programa de Iniciação Científica da Universidade São Francisco Telefone: (11) 4534-8040, fax: (11) 4524-1933

Rua Alexandre Rodrigues Barbosa, 45 - Itatiba - SP - 13251-040 bru.trevisan@ig.com.br

\section{Fernando César Capovilla}

Ph.D. em Psicologia Experimental pela Temple University, EUA; LivreDocente em Psicologia Clínica pela Universidade de São Paulo

Docente, pesquisador e orientador do Mestrado e Doutorado em Psicologia Experimental do Instituto de Psicologia da Universidade de São Paulo Instituto de Psicologia - Universidade de São Paulo Telefone: (11) 3091-4001

Av. Prof. Mello Moraes 1721 - São Paulo - SP - 05508-900.

capovilla@usp.br 


\section{Maria do Carmo Alves de Rezende}

Bolsista do Programa de Iniciação Científica da Universidade São Francisco Telefone: (11) 4534-8040, fax: (11) 4524-1933

Rua Alexandre Rodrigues Barbosa, 45 - Itatiba - SP - 13251-040 carmenrez@ig.com.br

\section{Como citar este artigo:}

CAPOVILLA, Alessandra Gotuzo Seabra et al. Natureza das dificuldades de leitura em crianças brasileiras com dislexia do desenvolvimento. Revista ACOALFAplp: Acolhendo a Alfabetização nos Países de Língua portuguesa, São Paulo, ano 1, n. 1, 2006. Disponível em: <http://www.acoalfaplp.net>. Publicado em: setembro de 2006. 